\title{
Maternal Overweight Downregulates MME (Neprilysin) in Feto-Placental Endothelial Cells and in Cord Blood
}

\author{
Elisa Weiß ${ }^{1}$, Hannah M. Berger ${ }^{1}$, Waltraud T. Brandl ${ }^{1}$, Jasmin Strutz ${ }^{1}$, Birgit Hirschmugl ${ }^{1}$, \\ Violeta Simovic ${ }^{1}$, Carmen Tam-Ammersdorfer ${ }^{2}{ }^{\mathbb{D}}$, Silvija Cvitic ${ }^{1}$ and Ursula Hiden ${ }^{1, *}$ \\ 1 Department of Obstetrics and Gynecology, Medical University of Graz, 8036 Graz, Austria; \\ elisa.weiss@medunigraz.at (E.W.); hannah121berger@gmail.com (H.M.B.); \\ waltraud.brandl@medunigraz.at (W.T.B.); jasmin.strutz@medunigraz.at (J.S.); \\ birgit.hirschmugl@medunigraz.at (B.H.); violeta.simovic@hotmail.com (V.S.); \\ silvija.cvitic@medunigraz.at (S.C.) \\ 2 Otto Loewi Research Center for Vascular Biology, Immunology and Inflammation, \\ Medical University of Graz, 8036 Graz, Austria; carmen.tam-amersdorfer@medunigraz.at \\ * Correspondence: ursula.hiden@medunigraz.at
}

Received: 9 December 2019; Accepted: 23 January 2020; Published: 28 January 2020

\begin{abstract}
Maternal overweight in pregnancy alters the metabolic environment and generates chronic low-grade inflammation. This affects fetal development and programs the offspring's health for developing cardiovascular and metabolic disease later in life. MME (membrane-metalloendopeptidase, neprilysin) cleaves various peptides regulating vascular tone. Endothelial cells express membrane-bound and soluble MME. In adults, the metabolic environment of overweight and obesity upregulates endothelial and circulating MME. We here hypothesized that maternal overweight increases MME in the feto-placental endothelium. We used primary feto-placental endothelial cells ( $\mathrm{fpEC}$ ) isolated from placentas after normal vs. overweight pregnancies and determined MME mRNA, protein, and release. Additionally, soluble cord blood MME was analyzed. The effect of oxygen and tumor necrosis factor $\alpha(\mathrm{TNF} \alpha)$ on MME protein in fpEC was investigated in vitro. Maternal overweight reduced MME mRNA $(-39.9 \%$, $p<0.05)$, protein $(-42.5 \%, p=0.02)$, and MME release from fpEC $(-64.7 \%, p=0.02)$. Both cellular and released MME protein negatively correlated with maternal pre-pregnancy BMI. Similarly, cord blood MME was negatively associated with pre-pregnancy BMI $(r=-0.42, p=0.02)$. However, hypoxia and $\mathrm{TNF} \alpha$, potential negative regulators of MME expression, did not affect MME protein. Reduction of MME protein in fpEC and in cord blood may alter the balance of vasoactive peptides. Our study highlights the fetal susceptibility to maternal metabolism and inflammatory state.
\end{abstract}

Keywords: MME; neprilysin; maternal overweight; feto-placental endothelial cells; umbilical cord blood

\section{Introduction}

Pregnancies complicated by maternal overweight are associated with an altered metabolic and endocrine environment and characterized by chronic low-grade inflammation [1,2]. These changes affect fetal development and, furthermore, program the offspring's health in the long term (reviewed by Ingvorsen et al. [3] and Zhou and Pan [4]). For instance, higher maternal pre-pregnancy BMI is associated with an increased childhood blood pressure [5,6] and an altered childhood cardiac structure [7]. Moreover, maternal overweight in pregnancy is positively associated with the development of cardiovascular disease in adult offspring [8]. Thus, although the mechanisms are not fully understood, there is a well-established association of maternal overweight and obesity with endothelial function and cardiovascular disease. Mechanisms may involve both direct mechanical effects of altered 
fetal hemodynamics on fetal cardiac development, as well as programming effects of the changed intrauterine environment on endothelial cells, cardiomyocytes, and smooth muscle cells.

MME (membrane metalloendopeptidase, also termed neprilysin and CD10) is an integral membrane-bound zinc metallo-endopeptidase that cleaves various vasoactive peptides and thus participates in blood pressure regulation [9]. Specifically, MME catalyzes degradation of several vasodilator peptides, including ANP, BNP, and CNP (natriuretic peptides A, B and C), adrenomodulin and bradykinin, as well as vasoconstrictor peptides such as endothelin-1 and angiotensin II (reviewed by Corti et al. [10]). Thus, the overall effect of MME on vascular tone regulation depends on the presence and composition of substrates within the specific vascular system [10].

MME is expressed on various cell types including endothelial cells [9]. Besides the membranebound form, a soluble form of MME exists that retains catalytic activity [11]. In fact, endothelial cells are a source of soluble MME [12]. Under metabolic derangements, soluble MME increases in the systemic circulation in adults, and correlates positively with BMI [13,14]. Various factors of the altered metabolic and pro-inflammatory environment contribute to this upregulation-in vitro experiments revealed that hyperglycemia and hyperlipidemia increase MME production in endothelial cells [15]. Additionally, the correlation of circulating MME levels with CRP (C-reactive peptide) reveals the susceptibility of MME to the pro-inflammatory environment, and pro-inflammatory mediators such as IL- $\beta 1$ (interleukin $\beta 1$ ) and TGF $\beta$ (transforming growth factor $\beta$ ) increase MME in various cell types [16-18].

We here hypothesized that maternal overweight upregulates MME in the fetal endothelium. To this end, we isolated primary human feto-placental endothelial cells after pregnancies of normal weight and overweight women and measured MME mRNA and protein.

\section{Results}

\subsection{Feto-Placental Endothelial Cells (fpEC) Expressed MME mRNA and Protein In Vivo and In Vitro}

To confirm MME protein production in placental endothelium, we performed immunohistochemistry of placental tissue. In fact, there was a positive staining for MME protein in the endothelium of the feto-placental vessels (Figure 1A). Furthermore, there was an intense MME staining also in the syncytiotrophoblast, the classical placental barrier that contacts the maternal bloodstream. Immunocytochemistry of isolated primary fpEC also further revealed production of MME in cultured fpEC (Figure 1B). Quantitative RT-PCR was used to compare $M M E$ expression levels of primary fpEC to $M M E$ expression in various classical MME-producing human organs (Figure 1C) and revealed feto-placental MME levels comparable to brain and thyroid. Total placental tissue revealed the highest expression of all analyzed organs, due to the intense MME expression in the syncytiotrophoblast. 

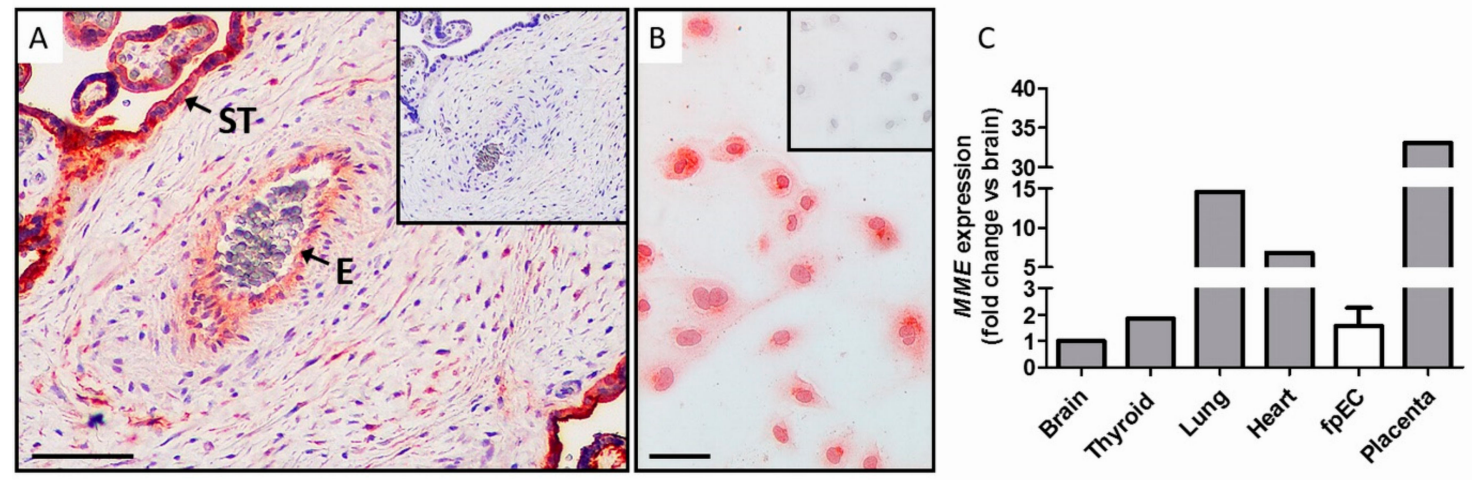

Figure 1. MME (membrane metalloendopeptidase) protein and mRNA expression in feto-placental endothelium. (A) In placental tissue, positive staining for MME (red) was detected in the syncytiotrophoblast (ST) facing the maternal circulation, as well as in the feto-placental endothelium (E) facing the fetal circulation. Nuclei were stained blue with DAPI (4',6-diamidino-2-phenylindole). Scale bar: $100 \mu \mathrm{m}$. (B) Immunocytochemistry revealed that isolated primary feto-placental endothelial cells (fpEC) continued to express MME in culture. Scale bar: $200 \mu \mathrm{m}$. Negative controls using unspecific mouse IgG are shown in the inserts. (C) Comparison of $M M E$ mRNA expression in different classical MME-producing tissues and organs, and in fpEC and placenta. Data were normalized to the mean of the house-keeping genes hypoxanthine-guanine phosphoribosyltransferase (HPRT1) and peptidylprolyl isomerase A (PPIA) and represented in relation to the expression in brain.

\subsection{Maternal Pre-Pregnancy Overweight Reduced MME $m R N A$ and Protein in fpEC}

Analysis of $M M E$ mRNA expression in primary fpEC isolated after pregnancies of women with normal vs. overweight BMI (Table 1) revealed a reduction of $M M E$ in fpEC exposed to overweight pregnancies $(-39.9 \%, p=0.047)$ (Figure $2 \mathrm{~A}$ ). This was paralleled by a reduction of cellular MME protein $(-42.5 \%, p=0.02)$ as well as secreted MME in the culture medium $(-64.7 \%, p=0.02)$ (Figure 2B,C). Whilst there was no significant correlation between fpEC MME mRNA expression and maternal pre-pregnancy BMI, cellular MME protein and MME secretion negatively correlated with BMI ( $r=-0.42, p=0.02$ and $r=-0.55, p=0.02$, respectively) (Figure 2D-F).

Table 1. Characteristics of the fpEC donors.

\begin{tabular}{ccc}
\hline Characteristics & Controls & Overweight Subjects \\
\hline Number of cases & 19 & 15 \\
Pre-pregnancy BMI $\left(\mathrm{kg} / \mathrm{m}^{2}\right)$ & $21.1 \pm 1.7$ & $28.7 \pm 3.4^{* * *}$ \\
BMI at birth $\left(\mathrm{kg} / \mathrm{m}^{2}\right)$ & $26.9 \pm 2.4$ & $33.9 \pm 2.6^{* * *}$ \\
Maternal age $(\mathrm{years})$ & $34.0 \pm 5.7$ & $32.3 \pm 4.1$ \\
oGTT $(0 \mathrm{~h})$ & $80.6 \pm 5.9$ & $82.9 \pm 4.7$ \\
oGTT $(1 \mathrm{~h})$ & $105.9 \pm 27.8$ & $116.5 \pm 27.8$ \\
oGTT $(2 \mathrm{~h})$ & $95.6 \pm 20.5$ & $94.1 \pm 16.3$ \\
Gestational age at delivery (weeks) & $39.7 \pm 1.0$ & $39.2 \pm 1.6$ \\
Mode of delivery (vaginal/C-section) & $8 / 11$ & $6 / 9$ \\
Fetal weight $(\mathrm{g})$ & $3559 \pm 351$ & $3477 \pm 402$ \\
Fetal height $(\mathrm{cm})$ & $51.5 \pm 1.7$ & $51.3 \pm 2.5$ \\
Fetal sex $(\mathrm{m} / \mathrm{f})$ & $12 / 7$ & $8 / 7$ \\
Placental weight $(\mathrm{g})$ & $634 \pm 117$ & $602 \pm 147$ \\
\hline
\end{tabular}

*** indicates $p<0.001$. oGTT: oral glucose tolerance test. 

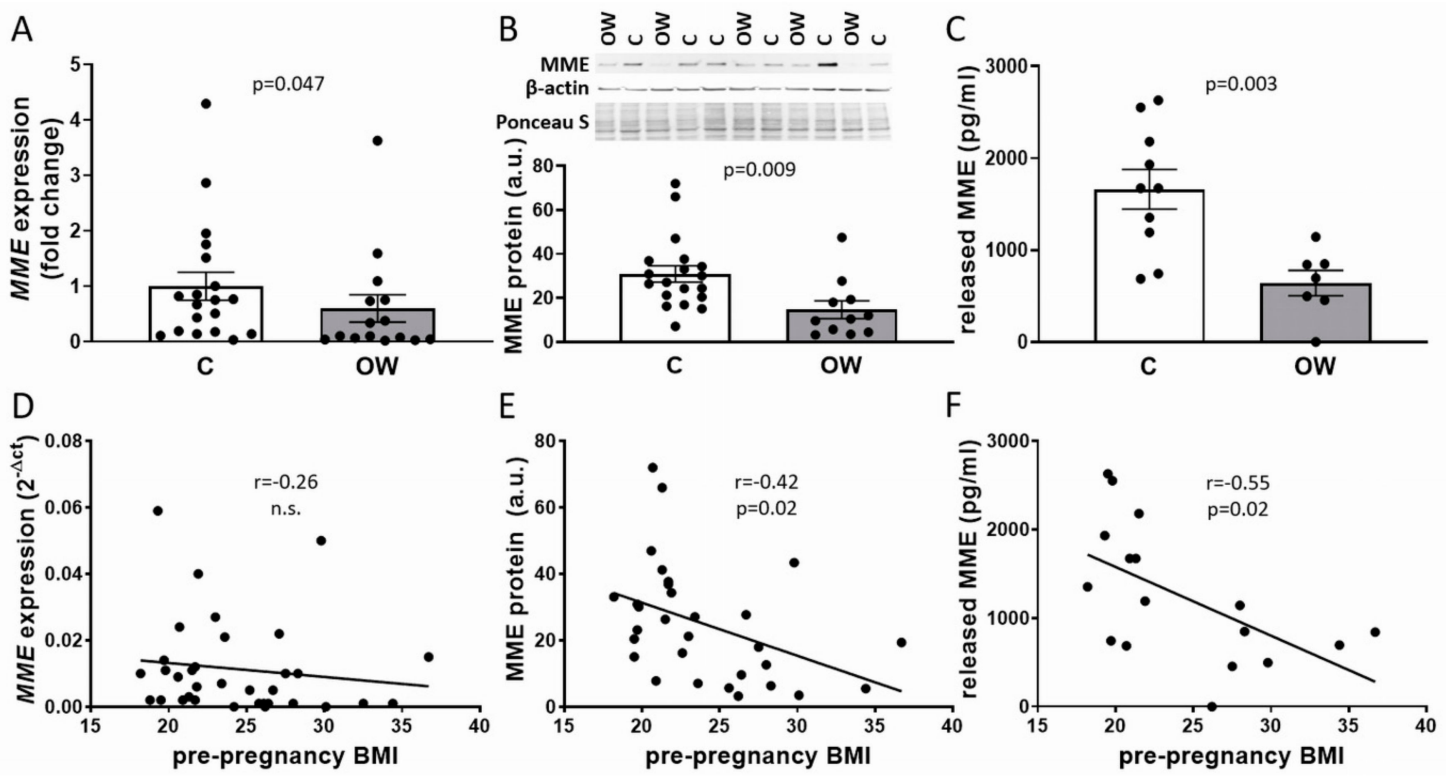

Figure 2. $M M E$ mRNA and protein in fpEC after normal and overweight pregnancy. $M M E$ mRNA (A), cellular protein (B), and released $\mathrm{MME}(\mathbf{C})$ was reduced in primary fpEC exposed to maternal overweight ( $t$-test). When correlated to maternal pre-pregnancy BMI (Pearson correlation), this association was not significant for fpEC MME mRNA (D), but it was significant for fpEC protein production (E) and release (F). MME mRNA was normalized to the mean of the housekeeping genes HPRT1 and ribosomal protein L30 (RPL30), respectively. A representative immunoblot for MME, $\beta$-actin, and the Ponceau $\mathrm{S}$ staining of the corresponding membrane are shown on top of the protein data in (B). C: controls; OW: overweight; a.u.: arbitrary units. MME mRNA: $n(\mathrm{c})=19 ; n(\mathrm{ow})=15$; cellular MME: $n(\mathrm{c})=19$; $n(\mathrm{ow})=11$; MME release: $n(\mathrm{c})=10 ; n(\mathrm{ow})=7$. The bars in $(\mathbf{A}-\mathbf{C})$ represent the mean $\pm \mathrm{SEM}$.

\subsection{Maternal Pre-Pregnancy Overweight Reduced Umbilical Cord Blood MME Levels}

Exposure to the intrauterine environment of overweight reduced MME release by fpEC in vitro. This raised the question as to whether maternal overweight also alters soluble MME in the fetal circulation. Thus, we collected a cohort of umbilical cord blood sera of pregnancies with normal vs. overweight pre-pregnancy BMI (Table 2). In parallel to the findings in isolated primary fpEC, MME in cord blood serum correlated negatively with maternal pre-pregnancy BMI (Figure 3).

Table 2. Characteristics of the cord blood donors.

\begin{tabular}{ccc}
\hline Characteristics & Controls & Overweight Subjects \\
\hline Number of cases & 20 & 12 \\
Pre-pregnancy BMI $\left(\mathrm{kg} / \mathrm{m}^{2}\right)$ & $21.4 \pm 1.2$ & $28.6 \pm 2.4^{* * *}$ \\
BMI at birth $\left(\mathrm{kg} / \mathrm{m}^{2}\right)$ & $26.7 \pm 2.1$ & $33.1 \pm 2.2^{* * *}$ \\
Maternal age $($ years $)$ & $31.1 \pm 5.3$ & $27.8 \pm 3.1$ \\
oGTT $(0 \mathrm{~h})$ & $81.1 \pm 5.7$ & $83.6 \pm 4.8$ \\
oGTT $(1 \mathrm{~h})$ & $123.5 \pm 34.7$ & $112.2 \pm 20.4$ \\
oGTT $(2 \mathrm{~h})$ & $98.8 \pm 24.4$ & $102.4 \pm 20.5$ \\
Maternal CRP at delivery & $2.8 \pm 1.9$ & $4.9 \pm 2.6^{*}$ \\
Gestational age at delivery (weeks) & $39.1 \pm 0.9$ & $38.9 \pm 0.9$ \\
Mode of delivery (vaginal/C-section) & $3 / 17$ & $1 / 11$ \\
Fetal weight $(\mathrm{g})$ & $3358 \pm 370$ & $3493 \pm 385$ \\
fetal height $(\mathrm{cm})$ & $50.5 \pm 2.1$ & $51.8 \pm 2.0$ \\
Fetal sex $(\mathrm{m} / \mathrm{f})$ & $10 / 10$ & $8 / 4$ \\
Placental weight $(\mathrm{g})$ & $667 \pm 89$ & $661 \pm 100$ \\
\hline
\end{tabular}

${ }^{*}$ indicates $p<0.5,{ }^{* * *}$ indicates $p<0.001$. 


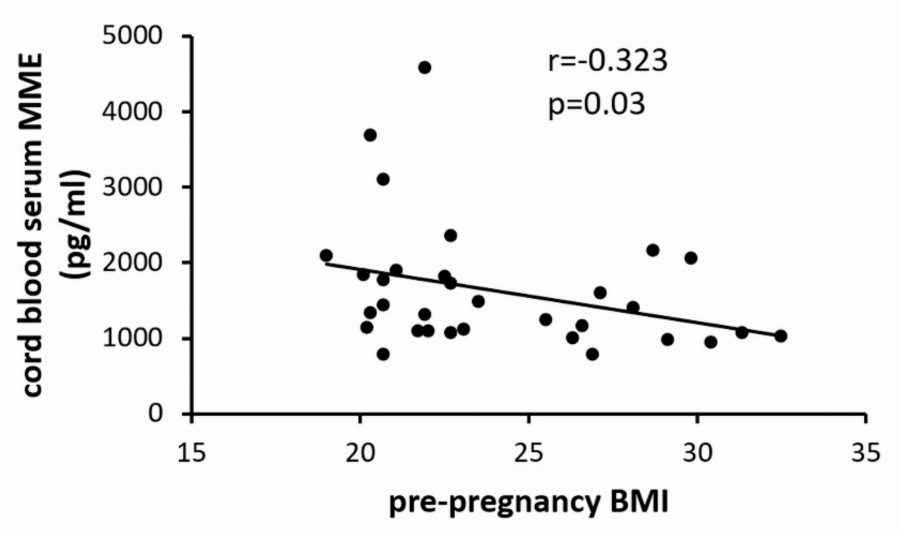

Figure 3. Correlation of umbilical cord blood serum MME levels with maternal pre-pregnancy BMI $(n=32)$.

This opposes findings in adults demonstrating upregulation of circulating MME with increasing BMI $[13,14]$. We therefore investigated whether the reduction of MME in cord blood serum is determined not by maternal BMI, but by fetal weight. However, similar to maternal BMI, neonatal weight also correlated negatively with cord blood MME (Figure 4).

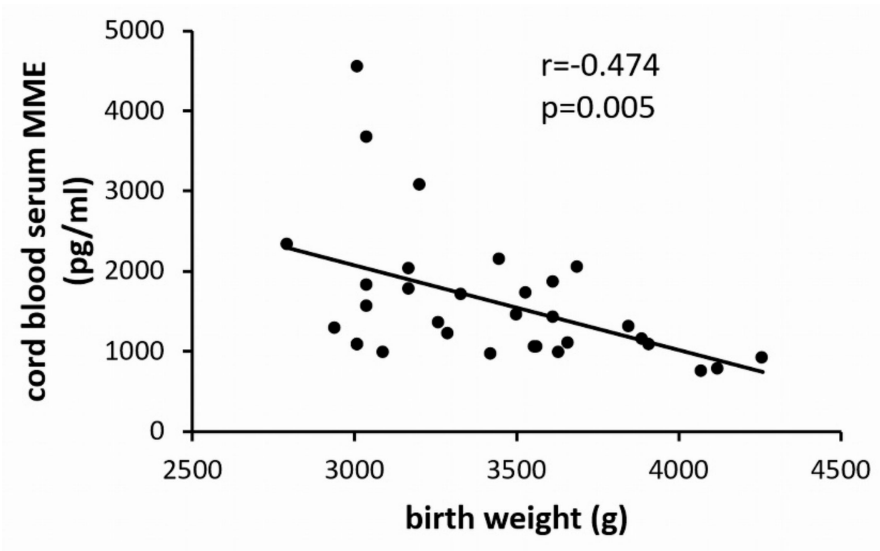

Figure 4. Correlation of umbilical cord blood serum MME levels with birth weight $(n=32)$.

\subsection{MME Protein in fpEC was not Regulated by Oxygen and Tumor Necrosis Factor $\alpha$ (TNF $\alpha$ )}

Hypoxia and NF-kB (nuclear factor kappa B) signalling downregulate MME in other cell types [19-21], and TNF $\alpha$ (tumor necrosis factor $\alpha$ ) is an activator of NF-kB signaling [22]. Thus, we tested whether oxygen or $\mathrm{TNF} \alpha$ altered MME in fpEC from control pregnancies. However, after $48 \mathrm{~h}, \mathrm{MME}$ protein did not differ between cells grown at $5 \%, 12 \%$, and $21 \%$ oxygen (Figure $5 \mathrm{~A})$. Additionally, TNF $\alpha$ treatment ( 5 and $50 \mathrm{ng} / \mathrm{mL}$ ) did not affect MME after $24 \mathrm{~h}$ (Figure 5B). 
A

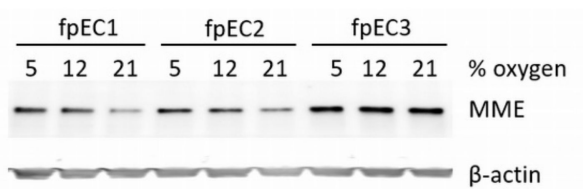

[at $=$ Ponceau S

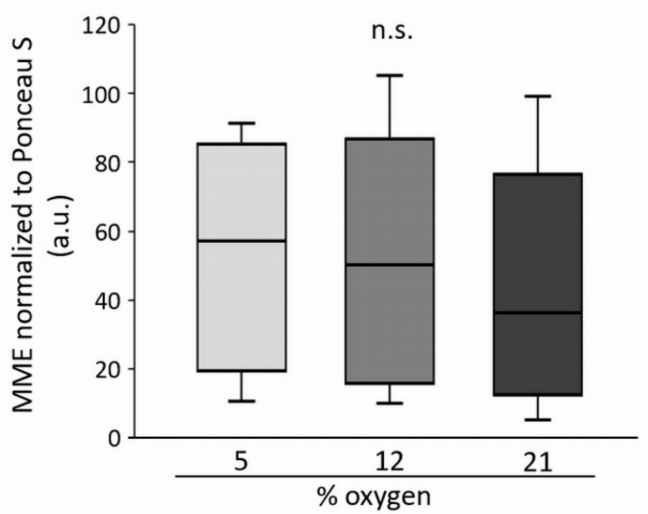

B

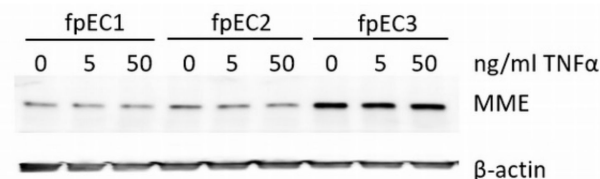

Ponceau S

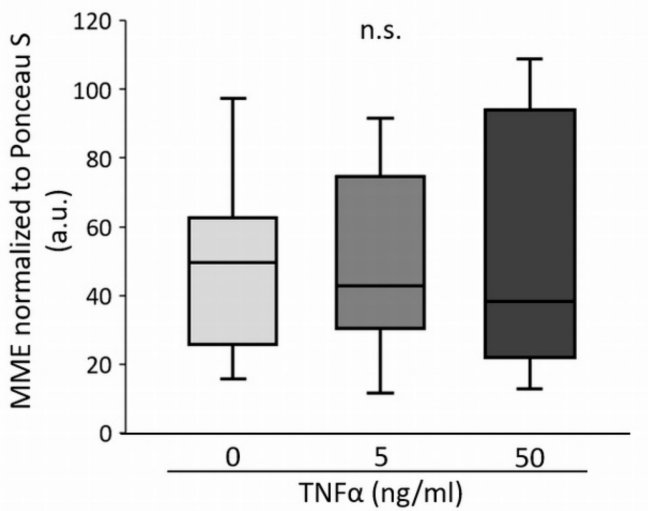

Figure 5. Effect of oxygen and tumor necrosis factor $\alpha(\mathrm{TNF} \alpha)$ on MME protein in fpEC. (A) MME protein after culture at $5 \%, 12 \%$, and $21 \%$ oxygen for $48 \mathrm{~h}$. (B) MME protein after TNF $\alpha$ treatment $(0$, 5 , and $50 \mathrm{ng} / \mathrm{mL}$ ) for $24 \mathrm{~h}$. Protein levels of $\beta$-actin were used as loading controls and protein was normalized to total protein staining with Ponceau S. Experiments were performed in $n=7$ different $\mathrm{fpEC}$ isolations. Representative immunoblots of three fpEC isolations are shown on top. a.u.: arbitrary units; $n . s .:$ not significant.

\section{Discussion}

Obesity and metabolic syndrome in adults are associated with increased levels of MME [13,14], and this may modulate vascular tone regulation. Upregulation of MME by fatty acids, glucose, and the pro-inflammatory environment represent a possible underlying reason [15-17]. In utero exposure to maternal overweight primes the offspring to a disturbed vascular tone regulation in childhood with elevated blood pressure and an adverse cardio-metabolic risk profile [3-8]. This study tested the hypothesis that the moderate metabolic derangement of maternal overweight in pregnancy increases the expression and release of MME by primary fpEC isolated from the feto-placental vasculature.

Surprisingly, maternal overweight reduced MME levels in endothelial cells and in the fetal circulation. In addition, fetal weight was negatively correlated with circulating cord blood serum MME. Despite normal maternal oGTT (oral glucose tolerance test) levels, maternal overweight and obesity in pregnancy are characterized by insulin resistance and increased levels of inflammatory markers, i.e., IL-6 [23] and CRP [24]. Additionally, in our overweight samples revealing only moderate metabolic derangement with normal oGTT, maternal CRP was increased (Table 2) and positively correlated with maternal pre-pregnancy BMI (Supplementary Figure S1). This altered maternal metabolic and pro-inflammatory environment translates also to the fetal circulation, as fetal insulin resistance, increased cord blood TNF $\alpha$, and CRP arise [25-28]. However, whilst insulin resistance and inflammatory status are associated with elevated MME in adults [16-18], other mechanisms seem to account for MME regulation in the fetal compartment.

Possible insults downregulating MME include hypoxia and NF-kB (nuclear factor kappa B) signaling. In rodents, hypoxia downregulates MME expression in the lungs, kidneys [20], and in the brain [21]. In fact, several studies have revealed a subtle hypoxic fetal environment in pregnancy complicated by maternal overweight $[29,30]$. Additionally, MME is downregulated by NF- $\kappa B$ pathway 
via microRNA miR155 in B-lymphoma cells [31]. The pro-inflammatory cytokine TNF $\alpha$ activates NF- $\mathrm{kB}$ pathway [22], which subsequently upregulates ICAM-1 (intercellular adhesion molecule 1) expression [32]. TNF $\alpha$ is increased in cord blood when mothers are overweight [27], and fpEC also respond to TNF $\alpha$ with an induction of ICAM-1 expression [33]. Thus, we further tested whether hypoxia or TNF $\alpha$ reduce MME protein in fpEC in vitro. However, both conditions did not affect MME protein, suggesting that neither hypoxia nor NF- $\mathrm{kB}$ participate in the overweight-associated reduction of MME. Fitzpatrick et al. [34] discovered that shear stress downregulates MME in aortic endothelial cells by a mechanism involving NADPH oxidase-dependent production of reactive oxygen species (ROS). Nonetheless, the unaffected expression of MME in fpEC exposed to different oxygen concentrations does not point towards a ROS-dependent signaling event accounting for MME reduction in overweight pregnancies. Besides signaling events, various studies have revealed epigenetic mechanisms underlying changes in fetal gene expression in response to an altered intrauterine environment. Such epigenetic mechanisms include DNA methylation and translational repression by miRNAs (reviewed by [35]). In fact, both mechanisms occur in MME regulation: Increased DNA methylation of the MME promoter region was observed in Alzheimer's disease brain [36] and in several types of cancer, such as leukemia [37] and breast cancer [38]. Additionally, MME is a target of miRNA-mediated regulation, as shown for the abovementioned miR155 [31]. Moreover, the miRNA target prediction database miRDB (www.mirdb.org) revealed that 156 different miRNAs potentially target MME mRNA, and thus may participate in its translational repression.

The physiological outcome of reduced endothelial and circulating MME can only be hypothesized and may be-in parallel with MME's multifunctional action—versatile. Reduced MME levels may affect the balance of vasoactive peptides, therefore affecting vascular tone regulation [10]. In fact, in human umbilical vein endothelium, MME effectively inactivates bradykinin, and hence impairs bradykinin-mediated vasodilatation [39]. However, depending on the presence and composition of MME vasoactive substrates within a certain vascular bed, and depending on the phenotype and responsiveness of the specific endothelial cells to these substrates [10], MME effects may differ in the fetus or neonate.

Moreover, recent literature suggests that elevated MME participates in the development of insulin resistance. On one hand, MME cleaves peptides stimulating insulin secretion, i.e., glucagon [40] and GLP1 (glucagon-like peptide 1) [41], and thus MME may reduce systemic insulin secretion [42]. On the other hand, membrane-associated MME modulates internalization and cellular localization of the insulin receptor, as shown by $M M E$ knockdown and overexpression in insulin target cells [43]. Hence, decreased levels of MME, as we observed in the overweight cohort, may play a role in the deregulation of insulin response and insulin resistance. In mice $M M E$, knockout results in increased insulin sensitivity [43]. However, neonates from pregnancies complicated by maternal obesity have increased insulin resistance [24]. Thus, the role and specific effect of reduced MME in feto-placental endothelium and cord blood on insulin secretion and resistance is difficult to predict.

Besides the regulation of vascular tone and insulin sensitivity, a role of MME in the regulation of angiogenesis was suggested. On one hand, MME cleaves and inactivates pro-angiogenic [44,45] as well as anti-angiogenic [46,47] acting growth factors and peptides. On the other hand, MME located at the cell membrane seems to participate in signaling events and has been shown to prevent FAK (focal adhesion kinase) activation and attenuates PKB (protein kinase B) signaling, causing reduced migration and angiogenesis (reviewed by Maguer-Satta et al. [48]). Several reports describe distinct placental vascular structure as a result of obesity in human and animals, with either increased [49-51] or decreased [52-54] vascularity, suggesting that placental angiogenesis and vascular development is susceptible towards maternal metabolic and pro-inflammatory changes, but the effective result may depend on the specific situation, i.e., moderate vs. severe metabolic changes. In any event, altered angiogenesis in the placenta will generate distinct placental vascular structure and architecture, ultimately affecting hemodynamics. This may contribute to functional programming of the fetal cardiovascular system. 
We see it as a limitation of our study that we do not have further metabolic and inflammatory information on the subjects, both from the maternal and from the fetal side. Data on maternal insulin resistance, fetal C-peptide, erythropoietin, and inflammatory markers would add significantly to the knowledge about the specific intrauterine stimulus downregulating MME and should be included in further studies.

Our study demonstrates for the first time that the moderate metabolic derangements of maternal overweight decreases feto-placental endothelial and fetal circulating MME, thus highlighting the susceptibility of the fetus to maternal metabolism and low-grade inflammation.

\section{Materials and Methods}

\subsection{Sample Collection}

Ethical approval was obtained from the Medical University of Graz (approval reference number 29-319 ex 16/17, 29.06.2017) and all women provided written informed consent. Placentas for feto-placental endothelial cell ( $\mathrm{fpEC}$ ) isolation were collected from pregnancies of non-smoking (self-reported) women with a negative $75 \mathrm{~g}$ oral glucose tolerance test (oGTT) performed at 25-28 weeks of gestation, free from any medical disorders or pregnancy complications. Control placentas were obtained from women with a pre-pregnancy BMI $<25$, overweight placentas were collected from women with a pre-pregnancy BMI $>25$. Table 1 shows the characteristics of the fpEC donors.

For the collection of umbilical cord blood serum, the same inclusion and exclusion criteria were used. Umbilical cord blood was collected directly after delivery, centrifuged at $3000 \mathrm{rpm}$ for $10 \mathrm{~min}$ at $4{ }^{\circ} \mathrm{C}$, and the serum was then stored at $-80^{\circ} \mathrm{C}$. Table 2 shows the characteristics of the cord blood donors.

\subsection{Cell Culture}

Primary arterial feto-placental endothelial cells (fpEC) were isolated from the collected placentas following a standard protocol [55]. Briefly, chorionic arteries were dissected and endothelial cells isolated by perfusion with a collagenase/dispase (Roche, Mannheim, Germany) solution. Cells were resuspended in endothelial basal medium (EBM, Lonza, Walkersville, MD, USA) supplemented with the EGM-MV BulletKit (Lonza) on 1\% (v/v) gelatin-coated flasks. Isolated fpECs were grown at $37^{\circ} \mathrm{C}$ and $12 \%$ oxygen, and used up to passage 10 . Cells were characterized by immunocytochemical analysis (c.f. below) with positive staining for the endothelial cell markers VWF (von Willebrand factor) and CD31, and negative for the SMA (smooth muscle actin) and the fibroblast marker CD90. For isolation of RNA, protein, and collection of supernatant, cells were grown in $75 \mathrm{~cm}^{2}$ flasks to approximately $90 \%$ confluency, washed with ice-cold Hank's balanced salt solution (HBSS; Gibco, Thermo Fisher Scientific, Runcorn, United Kingdom), and harvested as described below.

\subsection{Immunohistochemistry}

Immunohistochemical staining of MME was performed on standard formalin-fixed paraffin embedded term placenta sections $(5 \mu \mathrm{m})$. Standard deparaffinization procedure was followed by boiling slides in Epitope Retrieval Solution pH 9.0 (Novocostra, Leica, Vienna, Austria) for $7 \mathrm{~min}$ at $120^{\circ} \mathrm{C}$ in a decloaking chamber (Biocare Medical, Pacheco, CA, USA). Sections were immunostained using the UltraVision horseradish peroxidase (HRP) Polymer Kit (Thermo Fisher Scientific) according to the manufacturer's protocol. Briefly, endogenous peroxidase was blocked using the hydrogen peroxidase block for $10 \mathrm{~min}$. Three washing steps with Tris-buffered saline (TBS) were followed by background blocking using Ultra Vision Protein Block for $5 \mathrm{~min}$. Monoclonal mouse anti-CD10 antibody (Thermo Fisher Scientific) was diluted at 1:2000 in Antibody Diluent (Dako, Glostrup, Denmark) and incubated on slides for $45 \mathrm{~min}$ at RT (room temperature). Slides were washed and detection achieved by incubation with the anti-mouse/rabbit UltraVision HRP-labelled polymer system (15 $\mathrm{min}$ ) and 3-amino-9-ethylcarbacole (AEC, Thermo Fisher Scientific), according to the manufacturer's instructions. 
Nuclei were stained with Haemalaun solution (Sigma, St. Lois, MO, USA) and slides were mounted with aqueous mounting agent Aquatex (Merk Millipore, Darmstadt, Germany). For negative controls, slides were incubated with the same concentration of unspecific mouse IgG1 (Dako) as the primary antibody. Images were acquired using a Zeiss Axiophot microscope equipped with an AxioCamHRc digital camera.

\subsection{Immunocytochemistry}

Immunocytochemistry for quality control of $\mathrm{fpEC}$ and for MME was performed according to the same protocol. Cells (100,000 cells per $1.7 \mathrm{~cm}^{2}$ chamber) were grown on chamber slides for $48 \mathrm{~h}$, washed with HBSS, and fixed with ice-cold acetone (Merck, Darmstadt, Germany) for 3 min. Slides were rehydrated in Tris-borate EDTA (TBE) pH 7.5 with $0.1 \%$ Tween (Sigma) for 3 min, which was also used as a washing puffer. Non-specific binding sites were blocked with UltraVision Protein Block for $10 \mathrm{~min}$. Subsequently, the primary antibody for endothelial cell markers VWF (anti-VWF A0082, Dako; 1:3000) and CD31 (anti-CD31 MON6002-1, clone EN4, Monosan, Uden, the Netherlands; 1:300), smooth muscle cell marker SMA (anti-SMA M0851, clone 1A4, Dako, 1:200), fibroblast marker CD90 (anti-CD90, DIA100, clone AS02, Dianova, Hamburg, Germany; 1:200), and MME (anti-CD10; Thermo Fisher Scientific; 1:100) diluted in Dako antibody diluent was applied for $30 \mathrm{~min}$. Negative controls were of the same isotype and in the same dilution (Dako). After three washings, slides were incubated with HRP polymer for $15 \mathrm{~min}$ in the dark and washed again. Then, chromogenic reaction was started by addition of peroxidase-compatible chromogen (Thermo Fisher Scientific) for 5 min. After washing in distilled water, nuclei were stained with hematoxylin and mounted with Aquatex.

\subsection{Quantitative Reverse Transcription PCR (RT-qPCR)}

Total RNA was isolated using the miRNeasy mini kit (Qiagen, Hilden, Germany). The quality and integrity of the RNA was determined by the ratio of spectrophotometric absorbance $260 \mathrm{~nm} / 280 \mathrm{~nm}$ measured with the Scandrop 250 (Analytik Jena AG, Jena, Germany). Complementary DNA was transcribed from $1 \mu \mathrm{g}$ of total RNA using miScript II RT kit and 5× miScript HiFlex Buffer (Qiagen) according to the manufacturer's instructions.

For the quantification of $M M E$ mRNA in primary $\mathrm{fpEC}, 3 \mathrm{ng} / \mu \mathrm{L}$ of $\mathrm{cDNA}$ was used per reaction in a total reaction volume of $20 \mu \mathrm{L}$ in a CFX96 cycler (BioRad, Hercules, CA, USA). RT-qPCR for MME was performed using the TaqMan assay Hs00155310_m1 (Applied Biosystems, CA, USA) for $M M E$, and Hs02800695_m1 and Hs00265497_m1 (hypoxanthine-guanine phosphoribosyltransferase (HPRT1) and ribosomal protein L30 (RPL30), respectively) were used as housekeeping genes. For the quantification of $M M E$ mRNA in different human organs, $40 \mathrm{ng}$ of cDNA was used, which was transcribed from fpEC and purchased RNA from human tissues (Clonetech; Thermo Fisher Scientific). For the comparison of gene expression between different organs, the housekeeping genes HPRT1 (Hs02800695_m1) and peptidylprolyl isomerase A (PPIA, Hs04194521_s1) were used [56]. Mean expression of the housekeeping genes was used to normalize gene expression with $2^{-\Delta \Delta C \mathrm{t}}$ method.

\subsection{Immunoblot}

Total cellular protein was extracted with RIPA buffer containing proteinase inhibitors (Complete Protease Inhibitor Cocktail Tablets, Roche). Cell lysates (8 $\mu$ g per lane) were applied to a gradient 4-20\% SDS-PAGE, and transferred to $0.2 \mu \mathrm{m}$ nitrocellulose membranes (Trans-Blot Turbo Mini Nitrocellulose Transfer Membrane, BioRad) using the Trans-Blot Turbo Transfer System (BioRad). After transfer, membranes were incubated with Ponceau S solution (Sigma), which stained all transferred proteins. The membranes were photographed for protein normalization later. For detection of MME, mouse monoclonal anti-CD10 antibody (clone SN5c, Abcam, CA, USA) was used at a 1:1000 dilution. The secondary antibody was HRP-conjugated goat anti-mouse antibody (1:1000; R\&D Systems). Signals were detected using the SuperSignal West Pico (Pierce, Thermo Fisher Scientific). For control of antibody detection, membranes were incubated with mouse monoclonal anti- $\beta$-actin (1:20,000; clone 
AC-15, Abcam) followed by incubation with the HRP-conjugated secondary antibody (1:20,000). MME signals were detected at $85 \mathrm{kDa}$ and normalized to the Ponceau S-stained proteins in the molecular range between 40 and $100 \mathrm{kDa}$. Normalization of signals was performed with the signal intensity and was calculated by DigiDoc 1000 software.

\subsection{Enzyme-Linked Immunosorbent Assay (ELISA)}

For the collection of supernatants, fpEC were seeded $\left(15,000\right.$ cells $\left./ \mathrm{cm}^{2}\right)$ in T25 flasks and cultured for $48 \mathrm{~h}$. Then, supernatants were centrifuged at $3000 \mathrm{rpm}$ for $10 \mathrm{~min}$ and frozen at $-80{ }^{\circ} \mathrm{C}$ until the experiment. Absorbance of medium without cells incubated the same way was substracted from MME levels measured in the conditioned medium. Cord blood serum was obtained as described above. The human Neprilysin (MME) ELISA kit (Abnova, Taoyvan City, Taiwan) was performed according to the manufacturer's instructions. A total of $100 \mu \mathrm{L}$ of cell culture supernatants diluted at 1:4 and $100 \mu \mathrm{L}$ of cord blood serum were applied. Optical density was determined at $450 \mathrm{~nm}$ using a spectrophotometer (SPECTRO Analytical Instruments, Kleve, Germany).

\subsection{Hypoxia and TNF $\alpha$ Treatments}

To test the effect of hypoxia or TNF $\alpha$ on MME protein expression, fpEC ( $n=7$ different cell isolations, in duplicates) were seeded in gelatin coated 6-well plates (200,000 cells/well). Then, culture plates were placed at different oxygen concentrations $(21 \%, 12 \%$, and $5 \%)$ for $48 \mathrm{~h}$. For TNF $\alpha$ treatment, after overnight culture, cells were treated with TNF $\alpha$ ( 5 and $50 \mathrm{ng} / \mathrm{mL}$, Reliatech, Wolfenbüttel, Germany) for $24 \mathrm{~h}$. Cells without TNF $\alpha$ treatment served as the control. Protein was extracted with RIPA buffer containing proteinase inhibitors (complete), and immunoblotting for MME was performed as described above.

\subsection{Statistical Analysis}

Data were analyzed using GraphPad Prism software Version 5.01 (GraphPad Software, Inc). After testing for normal distribution (Kolmogorov-Smirnov test), Student's $t$-test and Pearson's test were applied to detect differences between the control and overweight samples and correlations, respectively. $p$-values below 0.05 were considered statistically significant.

Supplementary Materials: Supplementary materials can be found at http://www.mdpi.com/1422-0067/21/3/834/s1.

Author Contributions: Conceptualization, U.H.; methodology, E.W., H.M.B., W.T.B., J.S., B.H., V.S., C.T.-A.; formal analysis, E.W., S.C.; investigation, E.W., S.C.; writing-original draft preparation, U.H., E.W.; writing-review and editing, E.W., S.C., U.H. All authors have read and agreed to the published version of the manuscript.

Funding: U.H. was funded by a Jubileefund of the Oesterreichische Nationalbank (\#17238). This work was supported by the Austrian Science Fund FWF (DOC 31-B26) and the Medical University of Graz through the PhD Program Inflammatory Disorders in Pregnancy (DP-iDP).

Acknowledgments: Open Access Funding by the Austrian Science Fund (FWF).

Conflicts of Interest: The authors declare no conflict of interest.

\section{References}

1. Ramsay, J.E.; Ferrell, W.R.; Crawford, L.; Wallace, A.M.; Greer, I.A.; Sattar, N. Maternal obesity is associated with dysregulation of metabolic, vascular, and inflammatory pathways. J. Clin. Endocrinol. Metab. 2002, 87, 4231-4237. [CrossRef]

2. Pantham, P.; Aye, I.L.; Powell, T.L. Inflammation in maternal obesity and gestational diabetes mellitus. Placenta 2015, 36, 709-715. [CrossRef] [PubMed]

3. Ingvorsen, C.; Brix, S.; Ozanne, S.E.; Hellgren, L.I. The effect of maternal inflammation on foetal programming of metabolic disease. Acta Physiol. 2015, 214, 440-449. [CrossRef] [PubMed]

4. Zhou, D.; Pan, Y.X. Pathophysiological basis for compromised health beyond generations: Role of maternal high-fat diet and low-grade chronic inflammation. J. Nutr. Biochem. 2015, 26, 1-8. [CrossRef] [PubMed] 
5. Derraik, J.G.; Ayyavoo, A.; Hofman, P.L.; Biggs, J.B.; Cutfield, W.S. Increasing maternal prepregnancy body mass index is associated with reduced insulin sensitivity and increased blood pressure in their children. Clin. Endocrinol. 2015, 83, 352-356. [CrossRef] [PubMed]

6. Lawlor, D.A.; Najman, J.M.; Sterne, J.; Williams, G.M.; Ebrahim, S.; Davey Smith, G. Associations of parental, birth, and early life characteristics with systolic blood pressure at 5 years of age: Findings from the mater-university study of pregnancy and its outcomes. Circulation 2004, 110, 2417-2423. [CrossRef] [PubMed]

7. Toemen, L.; Gishti, O.; van Osch-Gevers, L.; Steegers, E.A.; Helbing, W.A.; Felix, J.F.; Reiss, I.K.; Duijts, L.; Gaillard, R.; Jaddoe, V.W. Maternal obesity, gestational weight gain and childhood cardiac outcomes: Role of childhood body mass index. Int. J. Obes. 2016, 40, 1070-1078. [CrossRef]

8. Eriksson, J.G.; Sandboge, S.; Salonen, M.K.; Kajantie, E.; Osmond, C. Long-term consequences of maternal overweight in pregnancy on offspring later health: Findings from the helsinki birth cohort study. Ann. Med. 2014, 46, 434-438. [CrossRef]

9. Turner, A.J.; Isaac, R.E.; Coates, D. The neprilysin (nep) family of zinc metalloendopeptidases: Genomics and function. Bioessays 2001, 23, 261-269. [CrossRef]

10. Corti, R.; Burnett, J.C., Jr.; Rouleau, J.L.; Ruschitzka, F.; Luscher, T.F. Vasopeptidase inhibitors: A new therapeutic concept in cardiovascular disease? Circulation 2001, 104, 1856-1862. [CrossRef]

11. Spillantini, M.G.; Sicuteri, F.; Salmon, S.; Malfroy, B. Characterization of endopeptidase 3.4.24.11 ("enkephalinase") activity in human plasma and cerebrospinal fluid. Biochem. Pharmacol. 1990, 39, 1353-1356. [CrossRef]

12. Kuruppu, S.; Rajapakse, N.W.; Minond, D.; Smith, A.I. Production of soluble neprilysin by endothelial cells. Biochem. Biophys. Res. Commun. 2014, 446, 423-427. [CrossRef] [PubMed]

13. Standeven, K.F.; Hess, K.; Carter, A.M.; Rice, G.I.; Cordell, P.A.; Balmforth, A.J.; Lu, B.; Scott, D.J.; Turner, A.J.; Hooper, N.M.; et al. Neprilysin, obesity and the metabolic syndrome. Int. J. Obes. 2011, 35, 1031-1040. [CrossRef] [PubMed]

14. Rice, G.I.; Jones, A.L.; Grant, P.J.; Carter, A.M.; Turner, A.J.; Hooper, N.M. Circulating activities of angiotensin-converting enzyme, its homolog, angiotensin-converting enzyme 2, and neprilysin in a family study. Hypertension 2006, 48, 914-920. [CrossRef]

15. Muangman, P.; Spenny, M.L.; Tamura, R.N.; Gibran, N.S. Fatty acids and glucose increase neutral endopeptidase activity in human microvascular endothelial cells. Shock 2003, 19, 508-512. [CrossRef]

16. Albrecht, M.; Doroszewicz, J.; Gillen, S.; Gomes, I.; Wilhelm, B.; Stief, T.; Aumuller, G. Proliferation of prostate cancer cells and activity of neutral endopeptidase is regulated by bombesin and il-1beta with il-1beta acting as a modulator of cellular differentiation. Prostate 2004, 58, 82-94. [CrossRef]

17. Tharaux, P.L.; Stefanski, A.; Ledoux, S.; Soleilhac, J.M.; Ardaillou, R.; Dussaule, J.C. Egf and tgf-beta regulate neutral endopeptidase expression in renal vascular smooth muscle cells. Am. J. Physiol. 1997, 272, C1836-C1843. [CrossRef]

18. Pavo, N.; Arfsten, H.; Cho, A.; Goliasch, G.; Bartko, P.E.; Wurm, R.; Freitag, C.; Gisslinger, H.; Kornek, G.; Strunk, G.; et al. The circulating form of neprilysin is not a general biomarker for overall survival in treatment-naive cancer patients. Sci. Rep. 2019, 9, 2554. [CrossRef]

19. Mitra, R.; Chao, O.S.; Nanus, D.M.; Goodman, O.B., Jr. Negative regulation of nep expression by hypoxia. Prostate 2013, 73, 706-714. [CrossRef]

20. Carpenter, T.C.; Stenmark, K.R. Hypoxia decreases lung neprilysin expression and increases pulmonary vascular leak. Am. J. Physiol. Lung Cell. Mol. Physiol. 2001, 281, L941-L948. [CrossRef]

21. Zhuravin, I.A.; Dubrovskaya, N.M.; Vasilev, D.S.; Kozlova, D.I.; Kochkina, E.G.; Tumanova, N.L.; Nalivaeva, N.N. Regulation of neprilysin activity and cognitive functions in rats after prenatal hypoxia. Neurochem. Res. 2019, 44, 1387-1398. [CrossRef]

22. Kiemer, A.K.; Weber, N.C.; Vollmar, A.M. Induction of ikappab: Atrial natriuretic peptide as a regulator of the nf-kappab pathway. Biochem. Biophys. Res. Commun. 2002, 295, 1068-1076. [CrossRef]

23. Christian, L.M.; Porter, K. Longitudinal changes in serum proinflammatory markers across pregnancy and postpartum: Effects of maternal body mass index. Cytokine 2014, 70, 134-140. [CrossRef] [PubMed]

24. Catalano, P.M.; Presley, L.; Minium, J.; Hauguel-de Mouzon, S. Fetuses of obese mothers develop insulin resistance in utero. Diabetes Care 2009, 32, 1076-1080. [CrossRef] [PubMed] 
25. Lemas, D.J.; Brinton, J.T.; Shapiro, A.L.; Glueck, D.H.; Friedman, J.E.; Dabelea, D. Associations of maternal weight status prior and during pregnancy with neonatal cardiometabolic markers at birth: The healthy start study. Int. J. Obes. 2015, 39, 1437-1442. [CrossRef]

26. International Association of Diabetes and Pregnancy Study Groups Consensus Panel; Metzger, B.E.; Gabbe, S.G.; Persson, B.; Buchanan, T.A.; Catalano, P.A.; Damm, P.; Dyer, A.R.; Leiva, A. International association of diabetes and pregnancy study groups recommendations on the diagnosis and classification of hyperglycemia in pregnancy. Diabetes Care 2010, 33, 676-682.

27. Dosch, N.C.; Guslits, E.F.; Weber, M.B.; Murray, S.E.; Ha, B.; Coe, C.L.; Auger, A.P.; Kling, P.J. Maternal obesity affects inflammatory and iron indices in umbilical cord blood. J. Pediatr 2016, 172, 20-28. [CrossRef]

28. Raguz, M.J.; Glamuzina, D.S.; Tomic, V.; Mikulic, I. Does the bmi of expectant mothers influence the concentration of c-reactive protein in newborns in the early neonatal period? Z Geburtshilfe Neonatol. 2016, 220, 251-256. [CrossRef]

29. Sheffer-Mimouni, G.; Mimouni, F.B.; Dollberg, S.; Mandel, D.; Deutsch, V.; Littner, Y. Neonatal nucleated red blood cells in infants of overweight and obese mothers. J. Am. Coll. Nutr. 2007, 26, 259-263. [CrossRef]

30. Richardson, B.S.; Ruttinger, S.; Brown, H.K.; Regnault, T.R.H.; de Vrijer, B. Maternal body mass index impacts fetal-placental size at birth and umbilical cord oxygen values with implications for regulatory mechanisms. Early Hum. Dev. 2017, 112, 42-47. [CrossRef]

31. Thompson, R.C.; Herscovitch, M.; Zhao, I.; Ford, T.J.; Gilmore, T.D. Nf-kappab down-regulates expression of the b-lymphoma marker cd10 through a miR-155/pu.1 pathway. J. Biol. Chem. 2011, 286, 1675-1682. [CrossRef] [PubMed]

32. Zhao, W.; Feng, H.; Guo, S.; Han, Y.; Chen, X. Danshenol a inhibits tnf-alpha-induced expression of intercellular adhesion molecule-1 (icam-1) mediated by nox4 in endothelial cells. Sci. Rep. 2017, 7, 12953. [CrossRef] [PubMed]

33. Diaz-Perez, F.I.; Hiden, U.; Gauster, M.; Lang, I.; Konya, V.; Heinemann, A.; Logl, J.; Saffery, R.; Desoye, G.; Cvitic, S. Post-transcriptional down regulation of icam-1 in feto-placental endothelium in gdm. Cell Adh. Migr. 2016, 10, 18-27. [CrossRef] [PubMed]

34. Fitzpatrick, P.A.; Guinan, A.F.; Walsh, T.G.; Murphy, R.P.; Killeen, M.T.; Tobin, N.P.; Pierotti, A.R.; Cummins, P.M. Down-regulation of neprilysin (ec3.4.24.11) expression in vascular endothelial cells by laminar shear stress involves nadph oxidase-dependent ros production. Int. J. Biochem. Cell Biol. 2009, 41, 2287-2294. [CrossRef] [PubMed]

35. Fernandez-Twinn, D.S.; Hjort, L.; Novakovic, B.; Ozanne, S.E.; Saffery, R. Intrauterine programming of obesity and type 2 diabetes. Diabetologia 2019, 62, 1789-1801. [CrossRef]

36. Nagata, K.; Mano, T.; Murayama, S.; Saido, T.C.; Iwata, A. DNA methylation level of the neprilysin promoter in alzheimer's disease brains. Neurosci. Lett. 2018, 670, 8-13. [CrossRef]

37. Ikawa, Y.; Sugimoto, N.; Koizumi, S.; Yachie, A.; Saikawa, Y. Dense methylation of types 1 and 2 regulatory regions of the cd10 gene promoter in infant acute lymphoblastic leukemia with mll/af4 fusion gene. J. Pediatr. Hematol. Oncol. 2010, 32, 4-10. [CrossRef]

38. Stephen, H.M.; Khoury, R.J.; Majmudar, P.R.; Blaylock, T.; Hawkins, K.; Salama, M.S.; Scott, M.D.; Cosminsky, B.; Utreja, N.K.; Britt, J.; et al. Epigenetic suppression of neprilysin regulates breast cancer invasion. Oncogenesis 2016, 5, e207. [CrossRef]

39. Nowak, W.; Errasti, A.E.; Armesto, A.R.; Santin Velazque, N.L.; Rothlin, R.P. Endothelial angiotensinconverting enzyme and neutral endopeptidase in isolated human umbilical vein: An effective bradykinin inactivation pathway. Eur. J. Pharmacol. 2011, 667, 271-277. [CrossRef]

40. Trebbien, R.; Klarskov, L.; Olesen, M.; Holst, J.J.; Carr, R.D.; Deacon, C.F. Neutral endopeptidase 24.11 is important for the degradation of both endogenous and exogenous glucagon in anesthetized pigs. Am. J. Physiol. Endocrinol. Metab. 2004, 287, E431-E438. [CrossRef]

41. Willard, J.R.; Barrow, B.M.; Zraika, S. Improved glycaemia in high-fat-fed neprilysin-deficient mice is associated with reduced dpp-4 activity and increased active glp-1 levels. Diabetologia 2017, 60, 701-708. [CrossRef] [PubMed]

42. Esser, N.; Barrow, B.M.; Choung, E.; Shen, N.J.; Zraika, S. Neprilysin inhibition in mouse islets enhances insulin secretion in a glp-1 receptor dependent manner. Islets 2018, 10, 175-180. [CrossRef] [PubMed] 
43. Ramirez, A.K.; Dankel, S.; Cai, W.; Sakaguchi, M.; Kasif, S.; Kahn, C.R. Membrane metallo-endopeptidase (neprilysin) regulates inflammatory response and insulin signaling in white preadipocytes. Mol. Metab. 2019, 22, 21-36. [CrossRef] [PubMed]

44. Goodman, O.B., Jr.; Febbraio, M.; Simantov, R.; Zheng, R.; Shen, R.; Silverstein, R.L.; Nanus, D.M. Neprilysin inhibits angiogenesis via proteolysis of fibroblast growth factor-2. J. Biol. Chem. 2006, 281, 33597-33605. [CrossRef] [PubMed]

45. Nauta, T.D.; van den Broek, M.; Gibbs, S.; van der Pouw-Kraan, T.C.; Oudejans, C.B.; van Hinsbergh, V.W.; Koolwijk, P. Identification of hif-2alpha-regulated genes that play a role in human microvascular endothelial sprouting during prolonged hypoxia in vitro. Angiogenesis 2017, 20, 39-54. [CrossRef] [PubMed]

46. Chen, H.; Levine, Y.C.; Golan, D.E.; Michel, T.; Lin, A.J. Atrial natriuretic peptide-initiated cgmp pathways regulate vasodilator-stimulated phosphoprotein phosphorylation and angiogenesis in vascular endothelium. J. Biol. Chem. 2008, 283, 4439-4447. [CrossRef] [PubMed]

47. Kuhn, M.; Volker, K.; Schwarz, K.; Carbajo-Lozoya, J.; Flogel, U.; Jacoby, C.; Stypmann, J.; van Eickels, M.; Gambaryan, S.; Hartmann, M.; et al. The natriuretic peptide/guanylyl cyclase-a system functions as a stress-responsive regulator of angiogenesis in mice. J. Clin. Invest. 2009, 119, 2019-2030. [CrossRef]

48. Maguer-Satta, V.; Besancon, R.; Bachelard-Cascales, E. Concise review: Neutral endopeptidase (cd10): A multifaceted environment actor in stem cells, physiological mechanisms, and cancer. Stem Cells 2011, 29, 389-396. [CrossRef]

49. Loardi, C.; Falchetti, M.; Prefumo, F.; Facchetti, F.; Frusca, T. Placental morphology in pregnancies associated with pregravid obesity. J. Matern. Fetal Neonatal. Med. 2016, 29, 2611-2616. [CrossRef]

50. Ma, Y.; Zhu, M.J.; Zhang, L.; Hein, S.M.; Nathanielsz, P.W.; Ford, S.P. Maternal obesity and overnutrition alter fetal growth rate and cotyledonary vascularity and angiogenic factor expression in the ewe. Am. J. Physiol. Regul. Integr. Comp. Physiol. 2010, 299, R249-R258. [CrossRef]

51. Hayes, E.K.; Lechowicz, A.; Petrik, J.J.; Storozhuk, Y.; Paez-Parent, S.; Dai, Q.; Samjoo, I.A.; Mansell, M.; Gruslin, A.; Holloway, A.C.; et al. Adverse fetal and neonatal outcomes associated with a life-long high fat diet: Role of altered development of the placental vasculature. PLoS ONE 2012, 7, e33370. [CrossRef] [PubMed]

52. Stuart, T.J.; O’Neill, K.; Condon, D.; Sasson, I.; Sen, P.; Xia, Y.; Simmons, R.A. Diet-induced obesity alters the maternal metabolome and early placenta transcriptome and decreases placenta vascularity in the mouse. Biol. Reprod. 2018, 98, 795-809. [CrossRef] [PubMed]

53. Hu, C.; Yang, Y.; Li, J.; Wang, H.; Cheng, C.; Yang, L.; Li, Q.; Deng, J.; Liang, Z.; Yin, Y.; et al. Maternal diet-induced obesity compromises oxidative stress status and angiogenesis in the porcine placenta by upregulating nox2 expression. Oxid. Med. Cell. Longev. 2019, 2019, 2481592. [CrossRef] [PubMed]

54. Bar, J.; Kovo, M.; Schraiber, L.; Shargorodsky, M. Placental maternal and fetal vascular circulation in healthy non-obese and metabolically healthy obese pregnant women. Atherosclerosis 2017, 260, 63-66. [CrossRef]

55. Lang, I.; Schweizer, A.; Hiden, U.; Ghaffari-Tabrizi, N.; Hagendorfer, G.; Bilban, M.; Pabst, M.A.; Korgun, E.T.; Dohr, G.; Desoye, G. Human fetal placental endothelial cells have a mature arterial and a juvenile venous phenotype with adipogenic and osteogenic differentiation potential. Differentiation 2008, 76, 1031-1043. [CrossRef]

56. Sharan, R.N.; Vaiphei, S.T.; Nongrum, S.; Keppen, J.; Ksoo, M. Consensus reference gene(s) for gene expression studies in human cancers: End of the tunnel visible? Cell Oncol. 2015, 38, 419-431. [CrossRef] [PubMed]

(C) 2020 by the authors. Licensee MDPI, Basel, Switzerland. This article is an open access article distributed under the terms and conditions of the Creative Commons Attribution (CC BY) license (http://creativecommons.org/licenses/by/4.0/). 